\title{
ANTI-HYPERGLYCEMIC AND ANTI-OXIDATIVE EFFECTS OF L-CARNITINE ADMINISTRATION IN ALLOXAN INDUCED DIABETIC ALBINO WISTAR RATS
}

\section{Rizwan Ali Talpur', Kumayl Abbas Meghji', Arsalan Ahmed Uqaili ${ }^{\circledR}$, Navaid Kazi', Ghulam Shah Nizammani ${ }^{2}$, Sumayya Qazi}

\begin{abstract}
OBJECTIVE: To evaluate anti-hyperglycemic and anti-oxidative effects of Lcarnitine in alloxan induced diabetic albino wistar rats.

METHODS: This quasi-experimental study was conducted at Isra University, Hyderabad from June 2017 to August 2017. Thirty-six albino wistar male rats were equally divided into 3 groups $(n=12$ /group); group $A$ (control), group $B$ (alloxan $150 \mathrm{mg} / \mathrm{kg}$ intraperitoneally) and group C (alloxan $150 \mathrm{mg} / \mathrm{kg}$ intraperitoneally $+\mathrm{L}$-carnitine $500 \mathrm{mg} / \mathrm{kg}$ orally for 21 days). Diabetes was induced in group B and C by single intraperitoneal dose of alloxan $150 \mathrm{mg} / \mathrm{kg}$ body weight and rats having blood glucose $>200 \mathrm{mg} / \mathrm{dl}$ were labeled as diabetic rats and included in study. Biochemical (blood glucose, serum insulin and glutathione peroxidase) and histopathological analysis of pancreas was performed in all three experimental groups.
\end{abstract}

RESULTS: Post-experimental body weight in groups $A, B$ and $C$ were noted as $249.58 \pm 6.63,199.08 \pm 12.18,210.58 \pm 5.14$ grams respectively. The fasting blood glucose in groups $A, B$ and $C$ were noted as $104.58 \pm 7.05,221.25 \pm 8.22$, I I $0.17 \pm 12.85 \mathrm{mg} / \mathrm{dl}$ respectively $(P<0.00 \mathrm{I})$. Serum insulin in groups $A, B$ and $C$ was noted as $1.45 \pm 0.083,0.31 \pm 0.16,1.74 \pm 0.23 \mathrm{ng} / \mathrm{ml}$ respectively $(P<0.00 \mathrm{I})$. Glutathione peroxidase levels in groups $A, B$ and $C$ were noted as $\mathrm{I} .45 \pm 0.17,0.93 \pm 0.1 \mathrm{I}, \mathrm{I} .74 \pm 0.17 \mathrm{ng} / \mathrm{ml}$ respectively $(\mathrm{P}<0.00 \mathrm{I})$. Histopathology of pancreas showed reduction in size (mean islet diameter $157 \pm 1.5 \mu \mathrm{m}$ ) and number of islets of Langerhans in diabetic rats, while Lcarnitine treated rats have shown compensatory increase in size of islets of Langerhans (mean islet diameter $210 \pm 6.3 \mu \mathrm{m}$ ).

CONCLUSION: L-carnitine therapy is a potent anti-hyperglycemic and antioxidative regimen capable of reducing blood glucose and increasing plasma antioxidant levels.

KEYWORDS: L-Carnitine (MeSH); Carnitine (MeSH); Diabetes (Non-MeSH); Oxidative Stress (MeSH); Pancreas (MeSH); Islets of Langerhans (MeSH); Reactive Oxygen Species (MeSH); Blood Glucose (MeSH); Insulin (MeSH); Glutathione Peroxidase (MeSH).

THIS ARTICLE MAY BE CITED AS: Talpur RA, Meghi KA, Uqaili AA, Kazi N, Nizammani GS, Qazi S. Anti-hyperglycemic and anti-oxidative effects of L-carnitine administration in alloxan induced diabetic albino wistar rats. Khyber Med Univ J 2019; I I (4):204-8. DOI: 10.35845/kmuj.2019.19II5

\section{INTRODUCTION}

D iabetes mellitus is a group of metabolic disorders defined as hyperglycemia due to insufficiency of secretion of insulin, action of insulin or combination of both. It is classified as diabetes mellitus type I and 2. Type I diabetes is caused by destruction of $\beta$ cells of pancreas which leads to absolute deficiency of insulin. Type 2 diabetes is caused by defect in secretion of insulin
I. Department of Physiology, Isra University, Hyderabad, Pakistan.

2. Department of Pathology, Isra University, Hyderabad, Pakistan.

3. Department of Biochemistry, Isra University, Hyderabad, Pakistan. Email『: arsalanuqaili@gmail.com Contact\#: +92-333-275570।

$\begin{array}{ll}\text { Date Submitted: } & \text { March 14, 2019 } \\ \text { Date Revised: } & \text { November 29, 2019 } \\ \text { Date Accepted: } & \text { November 30, 2019 }\end{array}$

with insulin resistance.' Alloxan is a toxic analogue of glucose which enters the $\beta$ cell using glucose transporter type 2 (GLUT-2). It induces diabetes through excessive formation of reactive oxygen species (ROS) which are highly toxic to $\beta$-cells and selectively destructs the insulin-producing $\beta$-cells in rodents and other animals. Glucokinase activity is also restricted by the alloxan. Alloxan diabetes is an insulin-dependent diabetes with characteristics features resembling the type I diabetes in humans. ${ }^{2,3}$ L-carnitine is a naturally occurring vitamin-like compound, is an ubiquitous constituent of human plasma and body tissues. L-carnitine performs a variety of essential intra-cellular and metabolic functions, like transport of fatty acid across the inner mitochondrial membrane into mitochondrial matrix for $\beta$-oxidation, detoxification of potentially toxic metabolites, regulation of mitochondrial acyl-CoA/free CoA ratio and stabilization of the cell membrane. ${ }^{4}$ In diabetic animal experimental models, pancreatic carnitine levels have been found decreased both in early and advanced stages of diabetes mellitus and excretion of carnitine in urine to increase. ${ }^{5} \mathrm{~L}$ carnitine short-circuit the Randle cycle by binding inhibitory acetyl-CoA units forming acetyl-carnitine and concomitantly releasing free CoA. Lowering of mitochondrial acetyl-CoA: free CoA ratio is than favorable for glucose oxidation. ${ }^{6}$ L-carnitine have got antioxidant properties by which it suppresses immune mediated responses by extinguishing ROS, as a result of that it inhibits the signaling for $T$ cell activation, this is how proinflammatory cytokine production is suppressed including IL-6. ${ }^{7} \mathrm{~L}$-carnitine is recommended at a dose of I-3 gram per 


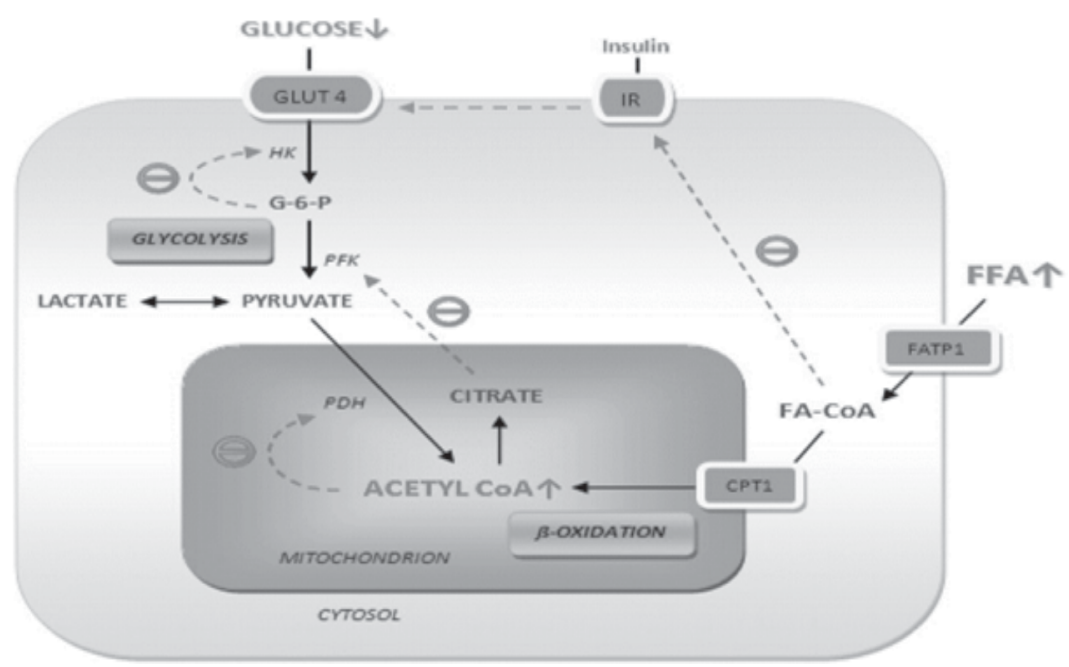

Figure I: Randle cycle showing inhibition of cellular glucose uptake ${ }^{8}$

day to adult individuals, supplementation with 2 gram Lcarnitine to hypothyroid patients have shown its effects associated with reduction in fatigue and better body composition.' Dosage upto $3000 \mathrm{mg} /$ day have been shown free of any side effect. ${ }^{10}$ Sensitivity of insulin can be enhanced with supplementation of Lcarnitine in over weight persons and in those who have impaired glucose tolerance, such as pre-diabetic individuals or those with metabolic syndrome." Serum carnitine level appears to be regulated in range between $23 \mu \mathrm{mol} / \mathrm{L}$ to $73 \mu \mathrm{mol} / \mathrm{L}$ while acetyl-L-carnitine appears to be in range between $3 \mu \mathrm{mol} / \mathrm{L}$ to $14 \mu \mathrm{mol} / \mathrm{L}$, both are present in serum independently of their dietary supplementation. ${ }^{12}$ Studies have suggested worthwhile effects of Lcarnitine supplements on inflammatory parameters, in secondary prevention of cardiovascular diseases, in management of diabetes mellitus, on control of serum lipid profile in patients on hemodialysis and for adult patients with end-stage renal disease on hemodialysis. ${ }^{13}$

The main objective of this study was to evaluate the anti-hyperglycemic and anti-oxidant effects of L-carnitine in alloxan induced diabetic albino wistar rats, evaluated by body weight, blood glucose, serum insulin, glutathione peroxidase (GPX) levels and histopathology of pancreas. Findings of this study will be significant in studying the effects of diabetes related metabolic disturbances and possible protective effects of L-carnitine in human populations.

\section{METHODS}

This quasi-experimental study was conducted at Isra University, Hyderabad from June 2017 to August 2017 after taking approval from Isra University Ethical Review Board. Sample of 36 albino wistar male rats were selected by nonrandom purposive sampling. The sample size was calculated using animal study sampling formula as described in previous studies. ${ }^{14}$ Inclusion criteria was healthy 250 grams. cages (with saw dust bedding). The cages were fully equipped with stainless steel feeding containers and plastic drinking bottles with stainless steel nozzles. The animals were housed in a hygienic and well ventilated environment. Rats were provided food (lab chow diet) and tap water ad libitum. The light/dark cycle was maintained at 12 hour intervals. Rats were equally divided into three groups. Group A was control group, group B was diabetic control group (alloxan $150 \mathrm{mg} / \mathrm{kg}$ i.p.) and group $C$ was experimental group (alloxan $150 \mathrm{mg} / \mathrm{kg}$ i.p. + L-carnitine $500 \mathrm{mg} / \mathrm{kg}$ orally for 21 days). Diabetes was induced in rats of group $B$ and $C$ by single intraperitoneal dose of alloxan $150 \mathrm{mg} / \mathrm{kg}$ body weight and diabetes induction was confirmed by serial blood glucose monitoring at 24, 48 and 72 hour interval after induction dose. Rats having blood non-diabetic male rats weighing 200 to

Animals were housed in the stainless steel glucose $>200 \mathrm{mg} / \mathrm{dl}$ were labeled as diabetic rats and included in study. ${ }^{15}$ The level of the orally administered dosage of L-carnitine $(500 \mathrm{mg} / \mathrm{kg}$ bwt) and intraperitoneal dose of alloxan $(150 \mathrm{mg} / \mathrm{kg}$ bwt intraperitoneally) was based on the previous works. ${ }^{16,17}$ Experimental work was conducted as per rules maintained by Ethical Committee of Isra University, Hyderabad. Body weights of all group rats were recorded before and after the experiment.

At the end of experiment all the rats were given anesthesia (chloroform soaked cotton) and sacrificed by cervical dislocation. Blood samples for biochemical analysis were collected by cardiac puncture. The samples were transferred to gel tubes and centrifuged at $3000 \mathrm{rpm}$ for $15 \mathrm{~min}$ at $4^{\circ} \mathrm{C}$ to separate serum which was stored in serum cups for biochemical analysis. Incision was given from the suprasternal notch to lower abdomen and the pancreas was removed and preserved in 10\% formalin. Tissue samples were passed through ascending grades of ethyl alcohol (70\%, $80 \%, 90 \%$ and $100 \%$ ) for dehydration purpose. After passing the samples through xylene for clearing, they were embedded in paraffin wax and 4 micron thick sections were obtained by microtome. Slides were stained with hematoxylin and eosin (H\&E) and observed under light microscope for morphological changes in pancreatic islets of Langerhans.

Blood glucose was measured using AccuCheck ${ }^{\circledR}$ advantage blood glucose monitor. Serum insulin was analyzed using DIAsource ImmunoAssay, Belgium ELISA kit (Ref no: KAPI25I) and GPX was analyzed using Bioassay Technology Laboratory, Shanghai, China ELISA kit (catalogue no: EI 242Ra) at Isra University diagnostic laboratory. SPSS (Statistical Packages for Social Sciences) version 22.0 was used for data analysis using ANOVA and student t-test at $95 \%$ confidence interval. Statistical significance was taken at $\mathrm{p}$ value $\leq 0.05$.

\section{RESULTS}

Blood glucose, serum insulin, GPX and body weight were measured and histopathology of pancreas was done in all rats. Mean body weight in control group was noted as $249.58 \pm 6.63$ grams, it was decreased in diabetic group to $199.08 \pm 12.18$ grams while in L-carnitine treated group it was $210.58 \pm 5$. 14 grams. 
TABLE I: BODY WEIGHT DISTRIBUTION OF THE EXPERIMENTAL GROUPS ( $n=12 /$ GROUP)

\begin{tabular}{|l|c|c|c|}
\hline Groups & Mean \pm SD (grams) & Minimum & Maximum \\
\hline Control Group & $249.58 \pm 6.63$ & 239 & 259 \\
\hline Diabetic Group & $199.08 \pm 12.18$ & 181 & 199 \\
\hline L-carnitine Treated & $210.58 \pm 5.14$ & 201 & 218 \\
\hline
\end{tabular}

TABLE II: DIFFERENCE IN BLOOD GLUCOSE, SERUM INSULIN AND GLUTATHIONE PEROXIDASE IN EXPERIMENTAL GROUPS

\begin{tabular}{|c|c|c|c|}
\hline Parameter & Groups & Mean \pm SD & P-Value \\
\hline \multirow{3}{*}{ Blood Glucose Level (mg/dl) } & Control & $104.58 \pm 7.05$ & \multirow{3}{*}{$<0.001$} \\
\hline & Diabetic & $221.25 \pm 8.22$ & \\
\hline & L-carnitine treated & $110.17 \pm 12.85$ & \\
\hline \multirow{3}{*}{ Serum Insulin Level ( $\mathrm{ng} / \mathrm{ml})$} & Control & $1.45 \pm 0.083$ & \multirow{3}{*}{$<0.001$} \\
\hline & Diabetic & $0.31 \pm 0.16$ & \\
\hline & L-carnitine treated & $1.74 \pm 0.23$ & \\
\hline \multirow{3}{*}{ Serum GPX Level (ng/ml) } & Control & $1.45 \pm 0.17$ & \multirow{3}{*}{$<0.00$} \\
\hline & Diabetic & $0.93 \pm 0.11$ & \\
\hline & L-carnitine treated & $1.74 \pm 0.17$ & \\
\hline
\end{tabular}

TABLE III: INDIVIDUAL COMPARISON OF BLOOD GLUCOSE, SERUM INSULIN AND GLUTATHIONE PEROXIDASE LEVELS IN DIABETIC GROUP AND L-CARNITINE TREATED GROUP

\begin{tabular}{|l|c|c|c|c|}
\hline Parameter & Group-B & Group-C & T-Score & P-Value \\
\hline Blood Glucose Level $(\mathrm{mg} / \mathrm{dl})$ & $221.25 \pm 8.22$ & $\mathrm{I} 10.17 \pm 12.85$ & 26.34 & $<0.00 \mathrm{I}$ \\
\hline Serum Insulin Level $(\mathrm{ng} / \mathrm{ml})$ & $0.3 \mathrm{I} \pm 0.16$ & $1.74 \pm 0.23$ & 20.4 & $<0.00 \mathrm{I}$ \\
\hline Serum GPX Level $(\mathrm{ng} / \mathrm{ml})$ & $0.93 \pm 0.1 \mathrm{I}$ & $1.74 \pm 0.17$ & $\mathrm{II} .6$ & $<0.00 \mathrm{I}$ \\
\hline
\end{tabular}

GPX $=$ Glutathione Peroxidase

Decreased weight loss was noticed in Lcarnitine treated rats as compared to diabetic rats (Table I).

Statistically significant difference in mean blood levels of glucose was found in all groups $(p<0.001)$. Mean blood glucose was found to be markedly increased in alloxan (diabetic) group but was near normal in L-carnitine treated group (Table II). Similarly, statistically significant difference in mean blood levels of serum insulin and GPX levels was also seen in all groups $(p<0.001)$. Both serum levels of Insulin and GPX were reduced in alloxan (diabetic) group but were comparatively higher in experimental animals receiving L-carnitine administration (Table II).

Student t-test results has also shown statistically significant difference in blood glucose, serum insulin and GPX levels between alloxan induced diabetic groups and L-carnitine treated groups $(\mathrm{p}<0.00 \mathrm{I})$ (Table III).

Pancreatic $\beta$ cell protective effects of $L-$ carnitine are also evident by histopathology of pancreas in which alloxan induction caused shrinkage in size (mean islet diameter $157 \pm 1.5 \mu \mathrm{m}$ ) and Lcarnitine treatment in diabetic rats caused compensatory increase in size (mean islet diameter $210 \pm 6.3 \mu \mathrm{m}$ ). Similarly, on observation there also a marked reduction in number of islets of Langerhans of pancreas in alloxan treated diabetic rats as compared with L-carnitine group (Figure 2).

\section{DISCUSSION}

Diabetes mellitus is a multifactorial error of metabolism characterized by hyperglycemia due to insufficiency of secretion of insulin, action of insulin or combination of both.' Randle cycle is involved to cause hyperglycemia by accumulation of fatty acids in cytoplasm which directly inhibit the insulin receptor and inhibitory acyl-CoA in mitochondria which inhibit the action of enzymes phosphofructokinase and pyruvate dehydrogenase. Improper beta oxidation of fatty acids leads to excessive formation of reactive oxygen species and disturbed homeostasis due to hyperglycemia severely affects pancreatic $\beta$ cells of islets of Langerhans as they have got low antioxidant levels compared to other cells of body. ${ }^{18}$ L-carnitine short-circuit the Randle cycle by reacting inhibitory acylCoA making acyl-carnitine and increasing free CoA level that favors glucose oxidation ultimately hyperglycemia subsides and quenches ROS through its anti-oxidant properties leading to improvement in pancreatic $\beta$ cell mass and insulin levels. ${ }^{6}$

In our study we found that alloxan diabetes induced in albino wistar rats in characterized by raised blood glucose levels, reduced serum insulin levels and reduced GPX levels. Treatment of alloxan induced diabetic rats with L-carnitine led to decrease in blood glucose levels near to normal and improvement in serum insulin and GPX levels. Our findings are consistent with findings of Samir, et al and Sasaninejad, et al who also reported reduction in blood glucose level in Sprague Dawley rats. However we differs with the study conducted by Samir, et al in that he used high fructose diet and single dose of streptozosin $30 \mathrm{mg} / \mathrm{kg}$ intraperitoneally. ${ }^{19,20}$ Rise in serum insulin level was also found in a recent study conducted by Sadighara, et al in which Lcarnitine administration prevented diabetogenic activity in diabetic rats with concomitant decrease in blood glucose levels. ${ }^{21}$ Abuzahra, et al also found results consistent with our study where Lcarnitine has shown antioxidant properties by quenching ROS with significant decrease in malondialdehyde and significant increase in GPX, superoxide dismutase and catalase. ${ }^{22} \mathrm{Hall}$, et al found consistent finding with positive correlation between lean body mass and L-carnitine content of the body. ${ }^{23}$

Our results were inconsistent with a recent study conducted by AmiriMoghadam, et al who found weight loss in diabetics with administration of Lcarnitine therapy in a randomized double blind placebo-controlled clinical trial, while our study shows preventive effects of L-carnitine from weight loss. ${ }^{24}$ This deviation of the results from our study might be due to long duration of study for 3 months with calorie restricted diet. Nagy, et al found consistent histopathologic changes in diabetes induction by alloxan with decrease in size and number of islets of Langerhans of pancreas of rats. ${ }^{14,25} \mathrm{~L}$-carnitine treatment 

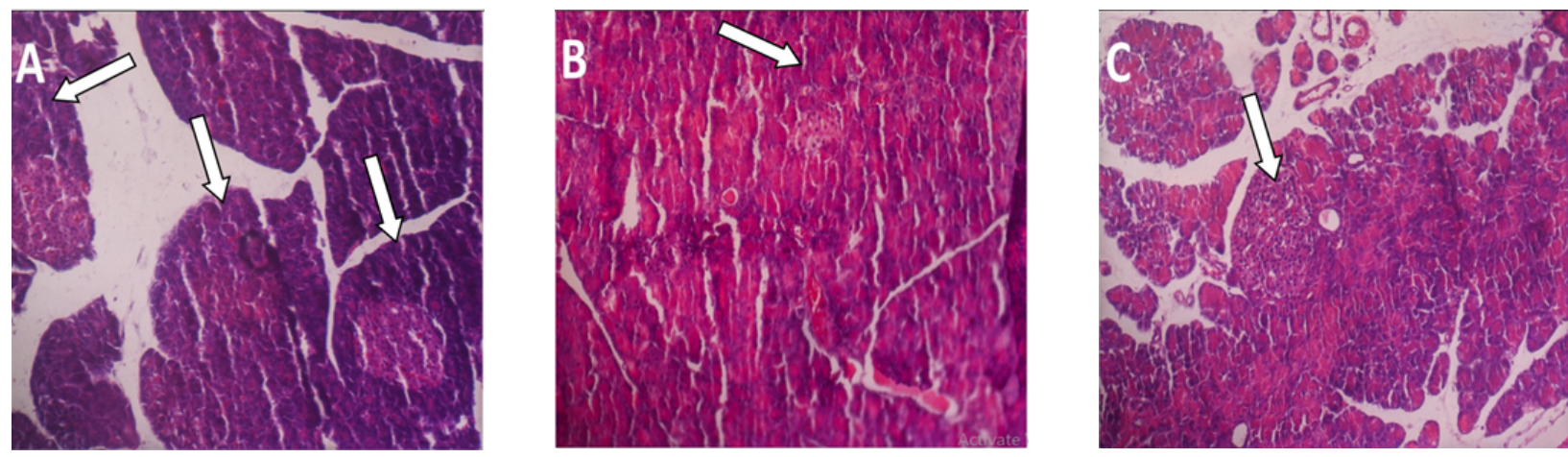

Figure 2: Section of pancreas of Experimental animals x 100 magnification. (A) Control group: showing normal architecture of beta cells of islets of Langerhans of pancreas. (B) Diabetic group: showing degenerative changes with shrinkage of size and reduced number of islets of Langerhans of pancreas. (C) L-carnitine treated diabetic group: showing regenerative changes by increase in size of islets of Langerhans of pancreas as compared to diabetic group.

in diabetic rats has shown its pancreatic $\beta$ cell protective effects by increase in size of islets of Langerhans of pancreas. This effects could be compensatory hypertrophy of islets of Langerhans of pancreas due to damage to the $\beta$ cell by alloxan induction.

However, there were certain limitations in the current study. Such as, limited availability of time, monetary resources due to which certain other parameters could not be included in the study protocol i-e inflammatory markers(Creactive protein, transforming growth factor, tumor necrosis factor etc.) and variable anti-oxidants (malondialdehyde, superoxide dismutase etc).

\section{CONCLUSION}

This study concludes that L-carnitine exerts an anti-hyperglycemic and antioxidative effect against alloxan-induced diabetes mellitus. Additionally, L-carnitine also shows cyto-protective effects on pancreatic $\beta$ cells.

\section{REFERENCES}

I. Jiskani SA, Khawaja SI, Talpur RA. Disturbances in Serum Electrolytes in Type 2 Diabetes Mellitus. National J Health Sci 2018;3(4):|29-3I. DOI: 10.21089/njhs.34.0128.

2. Lenzen S. The mechanisms of alloxanand streptozotocin-induced diabetes. Diabetologia 2008;5I(2):2 I6-26. DOI: 10.1007/s00 I25-007-0886-7.

3. Danilova I, Sarapultsev P, Medvedeva S, Gette I, Bulavintceva T, Sarapultsev
A. Morphological restructuring of myocardium during the early phase of experimental diabetes mellitus. Anat Rec (Hoboken) 2015;298(2):396407. DOI: I0.1002/ar.23052.

4. Derosa G, Limas CP, Macías PC, Estrella A, Maffioli P. Dietary and nutraceutical approach to type 2 $\mathrm{diabetes}$. Arch MedSci 20। 4; I0(2):336-42. DOI: I0.5 I |4/aoms.20I4.42587.

5. Salmanoglu DS, Gurpinar T, Vural K, Ekerbicer N, Darıverenli E, Var A. Melatonin and L-carnitin improves endothelial disfunction and oxidative stress in Type 2 diabetic rats. Redox Biol 2016;8:199-204. DOI: 10.1016/j.redox.2015.11.007.

6. Shiblawi WM, Ismael SH. The Effect of L-Carnitine as an Adjuvant Supplement on Lipid Profile in Iraqi Diabetic Patients. Iraqi J Pharm Sci 2015;24(2):48-52.

7. Humadi MHM, Mubarak ZM, Jamil IJ. The Effects of Leptin Hormone Concentrations and Some Immunological and Biochemical Parameters in Alloxan Induced Diabetic Male Rabbits and Diabetic Treated with Alpha Lipoic Acid and LCarnitine. Tikrit J Pure Sci 2018;22(2):I-7.

8. Delarue J, Magnan C. Free fatty acids and insulin resistance. Curr Opin Clin Nutr Metab Care 2007; I0(2): I42-8. DOI: 10.1097/MCO.0b0I3e328042 ba90.

9. An JH, Kim YJ, Kim KJ, Kim SH, Kim
$\mathrm{NH}$, Kim HY, et al. L-carnitine supplementation for the management of fatigue in patients with hypothyroidism on levothyroxine treatment: a randomized, doubleblind, placebo-controlled trial. Endocr J 20I6;63(I0):885-95. DOI: 10.1507/endocri.EJ16-0109.

10. Lee BJ, Lin JS, Lin YC, Lin PT. Antiinflammatory effects of $L$ carnitine supplementation (1000 $\mathrm{mg} / \mathrm{d}$ ) in coronary artery disease patients. Nutrition 20I5;3 I (3):475-9. DOI: I0.1016/j.nut.20I4.10.00I.

I I. Liu L, Zhang D, Wang M, Fan C, Zhou $F$, Wang $S$, et al. The adverse effects of Iong-term I-carnitine supplementation on liver and kidney function in rats. Hum Exp Toxicol 20|5;34(II): I|48-6I. DOI: |0.1|77/0960327||557|767.

12. Giesbertz P, Ecker J, Haag A, Spanier B, Daniel H. An LC-MS/MS method to quantify acylcarnitine species including isomeric and oddnumbered forms in plasma and tissues. J Lipid Res 2015;56( I0):202939. DOI: I0.1 | 94/jlr.D06 |72।.

13. Serban MC, Sahebkar A, Mikhailidis DP, Toth PP, Jones SR, Muntner P, et al. Impact of L-carnitine on plasma lipoprotein (a) concentrations: A systematic review and meta-analysis of randomized controlled trials. Sci Rep 2016;6:19188. DOI: 10.1038/ srep 19188.

14. Charan J, Kantharia N. How to calculate sample size in animal studies? J Pharmacol Pharmacother 
2013;4(4):303. DOI: 10.4103/0976$500 \times .119726$.

15. Mohammed A, Adelaiye A, Bakari A, Mabrouk M. Anti-diabetic and some haematological effects of ethylacetate and n-butanol fractions of Ganoderma lucidum aqueous extract in alloxan-induced diabetic wistar rats. Int J Med Med Sci 2009; I(I2): 530-5.

16. Cotter M, Cameron N, Keegan A, Dines K. Effects of acetyl-and proprionyl-L-carnitine on peripheral nerve function and vascular supply in experimental diabetes. Metabolism 1995;44(9):|209-14. DOI: 10.1016/ 0026-0495(95)900।8-7.

17. Sutradhar A, Sarkar AP, Saleh MA, Mondal M, Wahed TB, Ahmed S, et al. Investigation of antidiabetic and antilipidemic effect of fruit extract of Spondias pinnata (Amra) in alloxan induced hyperglycemic rats. J Pharmacog Phytochem 2018;7(5): 2785-9. DOI: I0.|3|40/RG.2.2. 28924.39045 .

18. Harijith A, Ebenezer DL, Natarajan V.
Reactive oxygen species at the crossroads of inflammasome and inflammation. Front Physiol 2014;5:352. DOI: 10.3389/fphys. 2014.00352 .

19. Samir SM, Abbas AM, Safwat SM, Elserougy HG. Effect of L-Carnitine on diabetes-induced changes of skeletal muscles in rats. J Basic Clin Physiol Pharmacol 2018;29(I):47-59. DOI: 10.15 I5/jbcpp-2016-0| 85 .

20. Sasaninejad Z, Eidi M, Khanehsar MA, Ghahramani R, Torabi F. Effect of LCarnitine on Serum Parameters in Alloxan-induced Diabetic male rats. Adv Biores 2015;6(3):120-3. DOI: |0.155|5/abr.0976-4585.6.3.120123.

21. Sadighara M, Joktaji JP, Hajhashemi V, Minaiyan M. Protective effects of coenzyme QIO and L-carnitine against statin-induced pancreatic mitochondrial toxicity in rats. Res Pharm Sci 2017;12(6):434-43. DOI: 10.4103/1735-5362.217424.

22. Abuzahra MAE-L, Mustafa SA-E. Nitric Oxide and Oxidative Stress
Properties of L-Carnitine in Diabetic Hypertensive Rats Biochemical and Histological Study. Middle East J Intern Med 2014;63(II98): I-13. DOI: I0.5742/MEIM.20I4.92498.

23. Hall JA, Yerramilli M, Obare E, Yerramilli M, Melendez LD, Jewell DE. Relationship between lean body mass and serum renal biomarkers in healthy dogs. J Vet Intern Med 2015;29(3):808-14. DOI: 10.1III/ jvim. 12607.

24. Amiri-Moghadam S, Nematy M, Eghtesadi S, Khalili M, Mojarrad M, Jazayeri S, et al. SUN-P06I: Effects of L-Carnitine Supplementation on Body Composition in Patients with Nonalcoholic Steatohepatitis. Clin Nutr 2017;36:S76. DOI: 10.1016/ S026I-56I4(I7)30566-6.

25. Nagy M. Antioxidant and antiapoptotic effects of Hydroclathrus clathratus on hepatic dysfunction in alloxan-induced Diabetes mellitus in male albino rats. Biochem: an Indian J (BCAIJ) 20I5;9(I):28-35.

\section{AUTHORS' CONTRIBUTIONS}

Following authors have made substantial contributions to the manuscript as under:

RAT: Conception and design, acquisition, analysis and interpretation of data, drafting the manuscript, final approval of the version to be published

KAM \& SQ: Acquisition of data, drafting the manuscript, final approval of the version to be published

AAU \& GSN: Analysis and interpretation of data, drafting the manuscript, final approval of the version to be published

NK: Acquisition of data, drafting the manuscript, critical review final approval of the version to be published

Authors agree to be accountable for all aspects of the work in ensuring that questions related to the accuracy or integrity of any part of the work are appropriately investigated and resolved.

CONFLICT OF INTEREST
Authors declared no conflict of interest
GRANT SUPPORT AND FINANCIAL DISCLOSURE
NIL

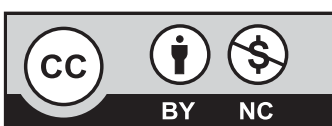

This is an Open Access article distributed under the terms of the Creative Commons Attribution-Non Commercial 2.0 Generic License.

KMUJ web address: www.kmuj.kmu.edu.pk

Email address: kmuj@kmu.edu.pk 